\title{
Atherogenic Index of Plasma, Triglyceride-Glucose Index and Monocyte-to-Lymphocyte Ratio for Predicting Subclinical Coronary Artery Disease
}

\section{Yueqiao Si}

Chengde Medical University Affiliated Hospital

\section{Wenjun Fan}

Chengde Medical University Affiliated Hospital

Chao Han

Chengde Medical University Affiliated Hospital

Jingyi Liu

Chengde Medical University Affiliated Hospital

Lixian Sun ( $D$ lixiansun01@126.com )

Chengde Medical University Affiliated Hospital

\section{Research Article}

Keywords: atherogenic index of plasma, triglyceride-glucose index, monocyte-to-lymphocyte ratio, coronary artery disease

Posted Date: May 21st, 2020

DOl: https://doi.org/10.21203/rs.3.rs-30212/v1

License: (9) (1) This work is licensed under a Creative Commons Attribution 4.0 International License. Read Full License

Version of Record: A version of this preprint was published at The American Journal of the Medical Sciences on May 1st, 2021. See the published version at https://doi.org/10.1016/j.amjms.2021.05.001. 


\section{Abstract}

Background: The atherogenic index of plasma (AIP), triglyceride-glucose (TyG) index, and monocyte-tolymphocyte ratio (MLR) are strongly associated with atherogenesis of the coronary artery. This study aimed to investigate the association of the AIP, TyG index, and MLR with subclinical coronary artery disease (CAD) and evaluate their ability to predict subclinical CAD.

Methods: A total of 697 asymptomatic patients were enrolled in this study and assigned to the subclinical CAD group $(n=332)$ and control group $(n=365)$. The clinical data, coronary artery calcification score, and calculated AIP, TyG index, and MLR were collected by graduate students in the cardiology division. Multivariate logistic regression models were set up to assess the risk factors for subclinical CAD.

Results: The AIP, TyG index and MLR values were higher in the subclinical CAD group than in the control group (all $P<0.05$ ). In addition to the classic independent clinical risk factors, increased AIP, TyG index and MLR values were all independent risk factors for subclinical CAD (all $P<0.05)$. The AUCs were higher after combining clinical risk factors than the AIP, TyG index, or MLR alone (all $P<0.05$ ).

Conclusions: The AIP, TyG index and MLR are independent risk factors for subclinical CAD, which can be useful for improving the diagnosis and prevention of CAD.

\section{Introduction}

Coronary artery disease (CAD) is the leading cause of death in cardiovascular disease, and the progression of coronary atherosclerosis leads to the onset of future cardiac events and is associated with a poor prognosis ${ }^{[1,2]}$. Acute adverse cardiovascular events occurring in asymptomatic subclinical CAD patients have been observed in the clinic. Therefore, identification of patients who are at risk of cardiovascular events is necessary before the onset of ischemic symptoms, as this could improve the prevention and treatment of CAD patients and reduce the occurrence of adverse CAD complications. Coronary artery calcification (CAC) is an established marker for subclinical atherosclerosis and $C A D^{[3]}$. Inflammation, abnormal glucose and lipid metabolism are critical in atherogenesis, and they are potent risk factors for cardiovascular disease ${ }^{[4,5]}$. Studies have shown that the atherogenic index of plasma (AIP), triglyceride-glucose (TyG) index, and monocyte-to-lymphocyte ratio (MLR) are new markers for atherosclerosis, insulin resistance and inflammation, respectively ${ }^{[6-8]}$. In this study, we investigated the association of the AIP, TyG index, and MLR with subclinical CAD and evaluated the ability of the AIP, TyG index, and MLR to predict subclinical CAD.

\section{Methods}

\section{Subjects and methods}


This was a retrospective, cross-sectional, and observational study, and a total of 697 asymptomatic patients in the cardiology clinic service were consecutively enrolled in this study from September 2015 to June 2017. All patients were divided into two groups: the subclinical CAD group (CAC score (CACS) $\geq 100$, $\mathrm{n}=335$ ) and the control group (CACS $=0, \mathrm{n}=362$ ). The major exclusion criteria were angina or myocardial infarction, history of percutaneous coronary intervention or other heart surgery, structural heart disease, and renal insufficiency. Subclinical $C A D^{[9]}$ was defined as a CACS $\geq 100$ Agatston Units and/or $\geq 50 \%$ coronary luminal stenosis.

\section{Demographic and clinical data}

Baseline demographic and clinical data for all patients were collected, including age, sex, height, weight, smoking, heart rate, systolic blood pressure, diastolic blood pressure, type 2 diabetes, hypertension, dyslipidemia, ischemic stroke, and so on. All patients underwent coronary computed tomographic angiography at the Affiliated Hospital of Chengde Medical University. The CACS was determined by the Agatston method, and the total Agatston CACS was calculated by summing all coronary arteries. The TyG index was calculated as In [fasting triglycerides $(\mathrm{mg} / \mathrm{dL}) \times$ fasting glucose $(\mathrm{mg} / \mathrm{dL}) / 2$ ]. The AIP was calculated as Ig (plasma triglyceride/high-density lipoprotein cholesterol). The MLR was calculated as monocyte/lymphocyte.

\section{Statistical analysis}

Continuous variables are expressed as quartile $M(Q R)$, and categorical variables are expressed as percentages. Continuous variables were compared using one-way analysis of variance, and categorical variables were compared using the $\chi^{2}$ test or Fisher's exact test. Receiver operating characteristic (ROC) curve analyses using the Youden index were employed to determine the optimal AIP, TyG index and MLR cut offs for predicting subclinical CAD. Univariate regression analysis was performed to evaluate the association between clinical variables and subclinical CAD. Multivariate logistic regression models 1, 2 , and 3 were established by adjusting the AIP, TyG index and MLR to determine the independent predictors of CAD. All statistical analyses were performed using the Statistical Package for Social Sciences software, version 19 (SPSS Inc., Chicago, IL, USA), and a P-value of $<0.05$ was considered significant for all analyses.

\section{Results}

\section{Clinical characteristics of the study cohort}

The median age of the 697 subjects (333 men, 47.8\%) was 60 years, and the median age of the subclinical CAD group was higher than that of the control group $(\mathrm{P}<0.001)$. The proportions of men and smoking and drinking behaviors were significantly higher in the subclinical CAD group than in the control 
group (all $\mathrm{P}<0.001$ ). Moreover, the prevalence of hypertension, type 2 diabetes, and ischemic stroke was significantly higher in the subclinical CAD group than in the control group (all $P<0.001$ ). The levels of hemoglobin and fasting blood glucose were higher in the subclinical CAD group than in the control group (both $\mathrm{P}<0.05$ ), as were levels of uric acid, creatinine, and blood urea nitrogen (all $\mathrm{P}<0.01$ ). Compared with those in the control group, the median AIP, TyG index and MLR values were higher in the subclinical CAD group (all $\mathrm{P}<0.05)$ (Table 1). 
Table 1

Clinical characteristics of subjects

\begin{tabular}{|c|c|c|c|c|}
\hline Variables & $\begin{array}{l}\text { Total } \\
(\mathrm{n}=697)\end{array}$ & $\begin{array}{l}\text { Subclinical CAD group } \\
(\mathrm{n}=335)\end{array}$ & $\begin{array}{l}\text { Control group } \\
(\mathrm{n}=362)\end{array}$ & $\mathrm{P}$ \\
\hline Male (\%) & $333(47.8)$ & $204(60.9)$ & $129(35.6)$ & $<0.001$ \\
\hline Age (year) & $60(54,65)$ & $63(59,68)$ & $56(51,61)$ & $<0.001$ \\
\hline Body mass index $(\mathrm{kg} / \mathrm{m} 2)$ & $\begin{array}{l}25.0(23.0 \\
27.3)\end{array}$ & $25.0(23.0,27.1)$ & $\begin{array}{l}24.9(22.9 \\
27.4)\end{array}$ & 0.978 \\
\hline Current smoking (\%) & $226(32.4)$ & $147(43.9)$ & $79(21.8)$ & $<0.001$ \\
\hline Hypertension (\%) & $384(55.3)$ & $226(67.5)$ & $158(43.9)$ & $<0.001$ \\
\hline Type 2 diabetes (\%) & $121(17.6)$ & $86(25.8)$ & $35(9.8)$ & $<0.001$ \\
\hline Dyslipidemia (\%) & $168(24.4)$ & $88(26.5)$ & $80(22.5)$ & 0.218 \\
\hline Ischemic stroke (\%) & $72(10.4)$ & $48(14.4)$ & $24(6.7)$ & 0.001 \\
\hline Heart rate (bpm) & $72(66,80)$ & $72(66,80)$ & $71(64,78)$ & 0.295 \\
\hline $\begin{array}{l}\text { Systolic blood pressure } \\
(\mathrm{mmHg})\end{array}$ & $\begin{array}{l}132(120 \\
150)\end{array}$ & $140(125,150)$ & $130(120,140)$ & $<0.001$ \\
\hline $\begin{array}{l}\text { Diastolic blood pressure } \\
(\mathrm{mmHg})\end{array}$ & $80(72,90)$ & $80(74,90)$ & $80(72,90)$ & 0.659 \\
\hline Left atrium diameter $(\mathrm{mm})$ & $33(30,37)$ & $34(31,38)$ & $33(30,35)$ & 0.004 \\
\hline $\begin{array}{l}\text { Left ventricle end-diastolic } \\
\text { diameter }(\mathrm{mm})\end{array}$ & $49(46,52)$ & $33(30,35)$ & $32(30,34)$ & 0.086 \\
\hline Hemoglobin (g/L) & $\begin{array}{l}140(130 \\
150)\end{array}$ & $142(132,152)$ & $138(129,148)$ & 0.027 \\
\hline Leukocyte $\left(10^{9} / \mathrm{L}\right)$ & $\begin{array}{l}6.31(5.21 \\
7.65)\end{array}$ & $6.61(5.52,7.90)$ & $\begin{array}{l}6.17(5.13 \\
7.63)\end{array}$ & 0.022 \\
\hline Lymphocyte (109/L) & $\begin{array}{l}1.86(1.49 \\
2.32)\end{array}$ & $1.84(1.43,2.33)$ & $\begin{array}{l}1.84(1.51 \\
2.29)\end{array}$ & 0.896 \\
\hline Monocyte $\left(10^{9} / \mathrm{L}\right)$ & $\begin{array}{l}0.42(0.31 \\
0.55)\end{array}$ & $0.44(0.34,0.59)$ & $\begin{array}{l}0.40(0.30 \\
0.52)\end{array}$ & 0.001 \\
\hline $\begin{array}{l}\text { Fasting blood glucose } \\
(\mathrm{mmol} / \mathrm{L})\end{array}$ & $\begin{array}{l}5.47(4.89, \\
6.60)\end{array}$ & $5.55(4.87,7.05)$ & $\begin{array}{l}5.43(4.90 \\
6.26)\end{array}$ & 0.026 \\
\hline Total cholesterol (mmol/L) & $\begin{array}{l}4.30(3.69, \\
5.00)\end{array}$ & $4.31(3.69,5.04)$ & $\begin{array}{l}4.29(3.69, \\
4.96)\end{array}$ & 0.611 \\
\hline Triglycerides (mmol/L) & $\begin{array}{l}1.52(1.05, \\
2.21)\end{array}$ & $1.54(1.13,2.25)$ & $\begin{array}{l}1.46(0.97 \\
2.13)\end{array}$ & 0.076 \\
\hline $\mathrm{HDL}-\mathrm{C}(\mathrm{mmol} / \mathrm{L})$ & $\begin{array}{l}1.11(0.92, \\
1.35)\end{array}$ & $1.10(0.93,1.31)$ & $\begin{array}{l}1.13(0.93, \\
1.40)\end{array}$ & 0.061 \\
\hline
\end{tabular}




\begin{tabular}{|c|c|c|c|c|}
\hline LDL-C (mmol/L) & $\begin{array}{l}2.38(1.84, \\
2.90)\end{array}$ & $2.40(1.86,2.95)$ & $\begin{array}{l}2.35(1.82 \\
2.84)\end{array}$ & 0.226 \\
\hline Uric acid (mmol/L) & $\begin{array}{l}303(251 \\
357)\end{array}$ & $316(268,370)$ & $290(239,344)$ & $<0.001$ \\
\hline Blood urea nitrogen (mmol/L) & $\begin{array}{l}5.31(4.43, \\
6.37)\end{array}$ & $5.52(4.55,6.43)$ & $\begin{array}{l}5.15(4.28, \\
6.23)\end{array}$ & 0.006 \\
\hline Creatinine $(\mu \mathrm{mol} / \mathrm{L})$ & $\begin{array}{l}64.5(55.4, \\
75.9)\end{array}$ & $67.5(57.3,77.9)$ & $\begin{array}{l}62.3(54.5 \\
72.4)\end{array}$ & $<0.001$ \\
\hline Statins (\%) & $461(66.1)$ & $289(86.3)$ & $172(47.6)$ & $<0.001$ \\
\hline$\beta$-blockers (\%) & $283(40.6)$ & $169(50.4)$ & $114(31.5)$ & $<0.001$ \\
\hline ACEI/ARB (\%) & $184(26.4)$ & $117(34.9)$ & $67(18.5)$ & $<0.001$ \\
\hline AIP & $\begin{array}{l}0.13(-0.07 \\
0.34)\end{array}$ & $0.16(-0.03,0.35)$ & $\begin{array}{l}0.11(-0.10 \\
0.35)\end{array}$ & 0.026 \\
\hline TyG index & $\begin{array}{l}8.80(8.39, \\
9.30)\end{array}$ & $8.86(8.44,9.40)$ & $\begin{array}{l}8.75(8.36, \\
9.20)\end{array}$ & 0.011 \\
\hline MLR & $\begin{array}{l}0.23(0.17 \\
0.31)\end{array}$ & $0.25(0.18,0.33)$ & $\begin{array}{l}0.21(0.16 \\
0.29)\end{array}$ & $<0.001$ \\
\hline
\end{tabular}

Data are presented as the number (\%) of patients and median (interquartile range).

Abbreviations: CACS: coronary artery calcification score, HDL-C: high-density lipoprotein cholesterol; LDLC: low-density lipoprotein cholesterol, AIP: atherogenic index of plasma, TyG: triglyceride-glucose, MLR: monocyte-to-lymphocyte ratio

\section{Association between clinical variables and subclinical CAD}

Univariate analysis showed that male sex, age $\geq 65$ years, smoking, drinking, hypertension, type 2 diabetes, and ischemic stroke were significantly associated with the risk of subclinical CAD. The risk of subclinical CAD was significantly higher in the increased AIP (OR 3.255, 95\% Cl 1.752-6.048, P< 0.001), increased TyG index (OR 2.123, 95\% Cl 1.236-3.646, $\mathrm{P}=0.006)$ and increased MLR (OR $1.871,95 \% \mathrm{Cl}$ 1.176-2.976, $\mathrm{P}=0.007$ ) groups (Table 2). 
Table 2

Association of clinical variables with subclinical CAD

\begin{tabular}{|lll|}
\hline Variables & \multicolumn{2}{l|}{ Univariate } \\
\cline { 2 - 3 } & OR $(95 \% \mathrm{Cl})$ & $\mathrm{P}$ \\
\hline Male & $2.813(2.069,3.825)$ & $<0.001$ \\
\hline Age $\geq 65$ years & $3.107(2.188,4.412)$ & $<0.001$ \\
\hline Current smoking & $2.801(2.014,3.895)$ & $<0.001$ \\
\hline Hypertension & $2.651(1.946,3.611)$ & $<0.001$ \\
\hline Type 2 diabetes & $3.193(2.084,4.892)$ & $<0.001$ \\
\hline Dyslipidemia & $1.244(0.878,1.763)$ & 0.218 \\
\hline Ischemic stroke & $2.330(1.392,3.899)$ & $<0.001$ \\
\hline AIP $\geq-0.253$ & $3.255(1.752,6.048)$ & $<0.001$ \\
\hline TyG index $\geq 8.04$ & $2.123(1.236,3.646)$ & 0.006 \\
\hline MLR $\geq 0.142$ & $1.871(1.176,2.976)$ & 0.007 \\
\hline
\end{tabular}

Abbreviations: AIP: atherogenic index of plasma, TyG: triglyceride-glucose, MLR: monocyte-to-lymphocyte ratio, $\mathrm{Cl}$ confidence interval, OR odds ratio.

\section{Multivariate logistic regression model adjustment of subclinical CAD}

Multivariate logistic regression models 1, 2, and 3 were adjusted as follows: model 1 was adjusted for male sex, age $\geq 65$, hypertension, type 2 diabetes, low-density lipoprotein cholesterol (LDL-C) $\geq 3.12$ $\mathrm{mmol} / \mathrm{L}$, and AIP $\geq-0.253$; model 2 was adjusted for male sex, age $\geq 65$ years, smoking, hypertension, type 2 diabetes, LDL-C $\geq 3.12 \mathrm{mmol} / \mathrm{L}$, and TyG index $\geq 8.04$; and model 3 was adjusted for age $\geq 65$, hypertension, type 2 diabetes, and MLR $\geq 0.142$. In addition to the classic independent risk factors, elevated AIP (OR 2.530, $P=0.01)$, TyG index (OR 2.007, $P=0.031$ ) and MLR (OR 1.693, $P=0.037)$ values were also found to be independent risk factors for subclinical CAD. The AIP had a greater impact on subclinical CAD than the TyG index and MLR (Table 3). 
Table 3

Comparison of laboratory indicators by study group

\begin{tabular}{|lll|}
\hline Variables & OR $(95 \% \mathrm{Cl})$ & $\mathrm{P}$ \\
\hline AIP $\geq-0.253^{\text {a }}$ & $2.530(1.252,5.114)$ & 0.010 \\
\hline TyG index $\geq 8.04^{\mathrm{b}}$ & $2.007(1.066,3.780)$ & 0.031 \\
\hline MLR $\geq 0.142^{\mathrm{c}}$ & $1.693(1.032,2.775)$ & 0.037 \\
\hline
\end{tabular}

Abbreviations: AIP: atherogenic index of plasma, TyG: triglyceride-glucose, MLR: monocyte-to-lymphocyte ratio, $\mathrm{Cl}$ confidence interval, OR odds ratio.

a: Model 1 Adjusted for male sex, age $\geq 65$, hypertension, type 2 diabetes, $L D L-C \geq 3.12 \mathrm{mmol} / \mathrm{L}$, AlP $\geq-0.253$.

b. Model 2 Adjusted for male sex, age $\geq 65$, smoking, hypertension, type 2 diabetes, LDL-C $\geq 3.12 \mathrm{mmol} / \mathrm{L}$, TyG index $\geq 8.04$.

C: Model 3 Adjusted for age $\geq 65$, hypertension, type 2 diabetes, $M L R \geq 0.142$.

\section{Receiver operating characteristic curve analysis}

The ROC analysis showed that the optimal AIP, TyG index, and MLR cutoff values for predicting subclinical CAD, as determined using the Youden index, were -0.253 (AUC: 0.548; 95\% Cl: $0.506-0.591 ; \mathrm{P}$ = 0.026; sensitivity: 95.8\%; specificity: 12.4\%), 8.04 (AUC: 0.556; 95\% Cl: $0.513-0.598 ; \mathrm{P}=0.011$; sensitivity: $93.7 \%$; specificity: $12.4 \%$ ), and 0.142 (AUC: 0.582 ; $95 \%$ Cl: $0.540-0.624 ; \mathrm{P}<0.001$; sensitivity: 90.1\%; specificity: $18.2 \%$ ) Figure 1). The predictive power of the AIP for subclinical CAD significantly improved after taking into account male sex, age, smoking, hypertension, type 2 diabetes, and LDL-C (AUC: 0.548 vs. $0.809 ; \mathrm{P}<0.05$ ). The predictive power of the TyG index for subclinical CAD significantly improved after taking into account male sex, age, hypertension, type 2 diabetes, and LDL-C (AUC: 0.556 vs. 0.803; $P<0.05)$. Finally, the predictive power of the MLR for subclinical CAD significantly improved after taking into account age, hypertension, and type 2 diabetes (AUC: 0.582 vs. $0.758 ; P<0.001$ ) (Table 4). 
Table 4

Comparison of ROC models related to the AIP, TyG index, and MLR for predicting subclinical CAD

\begin{tabular}{|llr|}
\hline ROC Models & AUC $(95 \% \mathrm{Cl})$ & $\mathrm{P}$ \\
\hline AIP & 0.548 & 0.026 \\
& $(0.506,0.591)$ & \\
\hline $\begin{array}{l}\text { AIP with male, age, current smoking, hypertension, type 2 diabetes, } \\
\text { LDL-C }\end{array}$ & $0.809(0.777$, & $<0.001$ \\
\hline TyG index & $0.841)$ & 0.011 \\
& 0.556 & \\
\hline TyG index with male, age, hypertension, type 2 diabetes, LDL-C & $0.513,0.598)$ & $<0.001$ \\
& $0.803(0.770$, & $<0.001$ \\
\hline MLR & $0.835)$ & $<0.001$ \\
\hline MLR with age, hypertension, type 2 diabetes & $0.582(0.540$, & \\
\hline
\end{tabular}

Abbreviations: LDL-C: low-density lipoprotein cholesterol, AIP: atherogenic index of plasma, TyG: triglyceride-glucose, MLR: monocyte-to-lymphocyte ratio

\section{Discussion}

Abnormal lipid metabolism, insulin resistance and the inflammatory response play important roles in the progression of coronary atherosclerosis, calcified plaque formation and deterioration ${ }^{[10,5]}$. This study explored these three aspects and evaluated the associations of the AIP, TyG index and MLR with subclinical CAD. Coronary artery calcification is a good marker for coronary atherosclerosis; the CACS indicates the coronary plaque burden, and subclinical CAD is usually defined by the CACS ${ }^{[11,12]}$. Atherosclerosis is a complicated process involving many mechanisms, such as inflammation, lipid accumulation, and insulin resistance. Chronic inflammation plays a key role in atherosclerosis, and lipoprotein cholesterol accumulation and insulin resistance promote inflammation and the formation of atherosclerotic plaques ${ }^{[13-15]}$. In this study, the main finding was that the AIP, TyG index and MLR were independent risk factors for subclinical CAD.

Lipid deposition in the intima is a key initial event in the development of atherosclerosis ${ }^{[16]}$, and the AIP is a new comprehensive lipid index that is superior to LDL-C, high-density lipoprotein cholesterol (HDL-C), total cholesterol, and triglyceride as a predictor for $C A D^{[17]}$. The AIP value increased as the triglyceride (TG) level increased and/or the HDL level decreased. Notably, the AIP is a substitute for SdLDL particles and is inversely related to LDL-C particle size ${ }^{[18]}$. An increase in the AIP indicates a reduction in LDL particle diameter and an increase in the proportion of sdLDL, which promotes the formation of foam cells and the development of atherosclerotic plaque ${ }^{[19]}$. Accumulating evidence suggests that the AIP is an important predictor for atherosclerosis and cardiovascular disease $\mathrm{e}^{[6,18,20]}$. 
Studies have reported that the TyG index is a better insulin resistance assessment tool than HOMA-IR and can be used as a predictor for CAD and adverse cardiovascular events ${ }^{[21-23]}$. The TyG index plays a potential role in all stages of CAD and affects the formation of atherosclerotic plaques, which is related to coronary artery calcification and coronary artery stiffness and could predict the degree of coronary artery stenosis ${ }^{[7,24]}$. Patients with insulin resistance had increased cardiovascular risk. Insulin resistance may directly and indirectly contribute to ventricular and vascular dysfunction, which is associated with

weakened proinflammatory responses and aggravated atherosclerotic plaques ${ }^{[25,26]}$. In addition, insulin resistance can alter systemic lipid metabolism, which then leads to the development of dyslipidemia, further aggravating vascular endothelial damage and inflammation and exacerbating the rupture of vulnerable plaques ${ }^{[27]}$.

Atherosclerosis is an inflammatory reaction triggered by lipid accumulation, and chronic inflammation is an important factor for the initiation, progression, and stability of atherosclerotic lesions ${ }^{[16]}$. The MLR, a new marker of systemic inflammation, is an independent risk factor for CAD and a predictive indicator of the severity of the lesions ${ }^{[28]}$. Previous studies have shown that the MLR is associated with

atherosclerosis and cardiovascular disease ${ }^{[29,30]}$. An increased MLR promotes body inflammation and oxidative stress, accelerates the formation of foam cells and endothelial damage, suppresses immune responses, promotes the formation and development of coronary plaques, and regulates the occurrence and development of $\mathrm{CAD}^{[31,32]}$.

The present study identified the AIP, TyG index and MLR as useful markers for predicting subclinical CAD. However, the AUC of the AIP, TyG index and MLR might be poor, suggesting that it is difficult to predict the presence of subclinical CAD based on any of these three markers alone. After considering clinical risk factors, the predictive value improved, which may be meaningful on a population level. This study explores subclinical CAD in terms of lipid accumulation, insulin resistance, and inflammation. Using the AIP, TyG index, and MLR to predict the prevalence of subclinical CAD might improve the screening and diagnosis of CAD patients and improve the prevention of thrombosis and stroke in asymptomatic patients.

Some limitations were present in our study. First, this was a single-center study, and all participants voluntarily visited the hospital for examination. Thus, selection bias may be present, and the results may not be generalizable to common populations. Second, the sample size of this study was small, and some clinical variables were not significantly different between the two groups. Therefore, a larger sample size and more comprehensive research are needed. Despite this limitation, the results still provide clinical implications in that we determined the predictive value of the AIP, TyG index, and MLR for subclinical CAD.

\section{Conclusion}

Increased AIP, TyG index and MLR values are independent risk factors and potential predictors for subclinical CAD. Using these noninvasive clinical markers to predict the prevalence of subclinical CAD 
could improve the diagnosis and prevention of CAD in asymptomatic patients.

\section{Abbreviations}

CAD: coronary artery disease, AIP: atherogenic index of plasma, TyG: triglyceride-glucose, MLR: monocyte-to-lymphocyte ratio, CACS: coronary artery calcification score, HDL-C: high-density lipoprotein cholesterol; LDL-C: low-density lipoprotein cholesterol

\section{Declaration}

\section{Acknowledgments}

The authors are grateful for the assistance of the cardiology doctors and nurses at the Affiliated Hospital of Chengde Medical University.

\section{Availability of data and materials}

Not applicable.

\section{Ethics approval and consent to participate}

This study was carried out in accordance with the World Medical Association's Code of Ethics (Helsinki Declaration) and approved by the Institutional Review Boards of the Affiliated Hospital of Chengde Medical University. All subjects provided written informed consent.

\section{Authors'contributions}

YS designed the study, performed the research, analyzed data, and wrote the paper. WF, JL and CH performed the experiments and collected the data. LS designed the study, discussed the results and revised the manuscript. All authors read and approved the final manuscript.

\section{Funding}

This study was supported by grants from Hebei Province Government Science and Technology Agency (Grant no. 17277769D) to Dr. Lixian Sun and 2020 Hebei Provincial Department of Education Graduate Innovation Funding Project (Grant no. CXZZSS2020126) to Yueqiao Si.

\section{Conflict of interest}

The authors declare that they have no competing interests.

\section{Consent for publication}

Not applicable. 


\section{References}

[1] Lee CH, Lee SW, Park SW. Diabetes and Subclinical Coronary Atherosclerosis. Diabetes Metab J. 2018;42(5):355-363.

[2] Lehmann N, Erbel R, Mahabadi AA, Rauwolf M, Möhlenkamp S, Moebus S, et al. Value of Progression of Coronary Artery Calcification for Risk Prediction of Coronary and Cardiovascular Events: Result of the HNR Study (Heinz Nixdorf Recall). Circulation. 2018;137(7):665-679.

[3] Osawa K, Nakanishi R, Budoff M. Coronary Artery Calcification. Glob Heart. 2016;11(3):287-293.

[4] Weber C, Noels H. Atherosclerosis: current pathogenesis and therapeutic options. Nat Med. 2011;17(11):1410-1422. Published 2011 Nov 7.

[5] Emamalipour M, Seidi K, Jahanban-Esfahlan A, Jahanban-Esfahlan R. Implications of resistin in type 2 diabetes mellitus and coronary artery disease: Impairing insulin function and inducing proinflammatory cytokines. J Cell Physiol. 2019;234(12):21758-21769.

[6] Cai G, Liu W, Lv S, Wang X, Guo Y, Yan Z, et al. Gender-specific associations between atherogenic index of plasma and the presence and severity of acute coronary syndrome in very young adults: a hospital based observational study[J]. Lipids Health Dis, 2019, 18(1):99.

[7] Alizargar J, Bai CH, Hsieh NC, Wu SV. Use of the triglyceride-glucose index (TyG) in cardiovascular disease patients[J]. Cardiovasc Diabetol, 2020, 19(1):8.

[8] Xiang F, Chen R, Cao X, Shen B, Liu Z, Tan X, et al. Monocyte/lymphocyte ratio as a better predictor of cardiovascular and all-cause mortality in hemodialysis patients: A prospective cohort study. Hemodialysis international International Symposium on Home Hemodialysis, 2018;22(1):82-92.

[9] Meeuwsen JAL, de Vries J, Zoet GA, Franx A, Fauser BCJM, Maas AHEM, et al. Circulating Neutrophils Do Not Predict Subclinical Coronary Artery Disease in Women with Former Preeclampsia. Cells. 2020;9(2):468. Published 2020 Feb 18.

[10] Stein R, Ferrari F, Scolari F. Genetics, Dyslipidemia, and Cardiovascular Disease: New Insights. Curr Cardiol Rep. 2019;21(8):68. Published 2019 Jun 21. .

[11] Vancheri F, Longo G, Vancheri S, Danial JSH, Henein MY. Coronary Artery Microcalcification: Imaging and Clinical Implications. Diagnostics (Basel). 2019;9(4):125. Published 2019 Sep 23.

[12] Shaikh K, Nakanishi R, Kim N, Budoff MJ. Coronary artery calcification and ethnicity. J Cardiovasc Comput Tomogr. 2019;13(6):353-359.

[13] Lu H, Daugherty A. Atherosclerosis. Arterioscler Thromb Vasc Biol. 2015;35(3):485-91 
[14] Peng J, Luo F, Ruan G, Peng R, Li X. Hypertriglyceridemia and atherosclerosis. Lipids Health Dis. 2017;16(1):233. Published 2017 Dec 6.

[15] Di Pino A, DeFronzo RA. Insulin Resistance and Atherosclerosis: Implications for Insulin-Sensitizing Agents. Endocr Rev. 2019;40(6):1447-1467.

[16] Farmer JA, Gotto AM Jr. Dyslipidemia and the vulnerable plaque. Prog Cardiovasc Dis. 2002;44(6):415-428.

[17] Wu TT, Gao Y, Zheng YY, Ma YT, Xie X. Atherogenic index of plasma (AIP): a novel predictive indicator for the coronary artery disease in postmenopausal women. Lipids Health Dis. 2018;17(1):197.

[18] Guo Q, Zhou S, Feng X, Yang J, Qiao J, Zhao Y, et al. The sensibility

of the new blood lipid indicator-atherogenic index of plasma (AIP) in menopausal women with coronary artery disease. Lipids Health Dis. 2020 Feb 24;19(1):27.

[19] Cure E, Cumhur Cure M. Comment on "The relationship between atherogenic index of plasma and no-reflow in patients with acute ST-segment elevation myocardial infarction who underwent primary percutaneous coronary intervention". Int J Cardiovasc Imaging. 2020;36(5):797-798.

[20] Cai G, Shi G, Xue S, Lu W. The atherogenic index of plasma is a strong and independent predictor for coronary artery disease in the Chinese Han population. Medicine (Baltimore). 2017;96(37):e8058.

[21] Cho YR, Ann SH, Won KB, Park GM, Kim YG, Yang DH, et al. Association between insulin resistance, hyperglycemia, and coronary artery disease according to the presence of diabetes. Sci Rep. 2019 Sep 2;9(1):6129.

[22] da Silva A, Caldas APS, Hermsdorff HHM, Bersch-Ferreira ÂC, Torreglosa CR, Weber B, et al. Triglyceride-glucose index is associated with symptomatic coronary artery disease in patients in secondary care. Cardiovasc Diabetol. 2019;18(1):89. Published 2019 Jul 11.

[23] Jin JL, Cao YX, Wu LG, You XD, Guo YL, Wu NQ, et al. Triglyceride glucose index for predicting cardiovascular outcomes in patients with coronary artery disease. J Thorac Dis. 2018;10(11):6137-6146.

[24] Won KB, Kim YS, Lee BK, Heo R, Han D, Lee JH, et al. The relationship of insulin resistance estimated by triglyceride glucose index and coronary plaque characteristics. Medicine (Baltimore). 2018;97(21):e10726.

[25] Novo G, Manno G, Russo R, Buccheri D, Dell'Oglio S, Morreale P, et al. Impact of insulin resistance on cardiac and vascular function. Int J Cardiol. 2016;221:1095-1099.

[26] Montecucco F, Steffens S, Mach F. Insulin resistance: a proinflammatory state mediated by lipidinduced signaling dysfunction and involved in atherosclerotic plaque instability. Mediators Inflamm. 
[27] Ormazabal V, Nair S, Elfeky O, Aguayo C, Salomon C, Zuñiga FA. Association between insulin resistance and the development of cardiovascular disease. Cardiovasc Diabetol. 2018 Aug 31;17(1):122.

[28] Wen Y, Zhan X, Wang N, Peng F, Feng X, Wu X. Monocyte/Lymphocyte Ratio and Cardiovascular Disease Mortality in Peritoneal Dialysis Patients. Mediators Inflamm. 2020;2020:9852507.

[29] Gijsberts CM, Ellenbroek GHJM, Ten Berg MJ, Huisman A, van Solinge WW, Lam CS, et al. Effect of Monocyte-to-Lymphocyte Ratio on Heart Failure Characteristics and Hospitalizations in a Coronary Angiography Cohort. Am J Cardiol. 2017;120(6):911-916.

[30] Fan Z, Ji H, Li Y, Jian X, Li L, Liu T. Relationship between

monocyte-to-lymphocyte ratio and coronary plaque vulnerability in patients with stable angina. Biomark Med. 2017;11(11):979-990.

[31] Shaw DM, Merien F, Braakhuis A, Dulson D. T-cells and their cytokine production: The antiinflammatory and immunosuppressive effects of strenuous exercise. Cytokine. 2018;104:136-142.

[32] Register TC, Appt SE, Clarkson TB. Atherosclerosis and Vascular Biologic Responses to Estrogens: Histologic, Immunohistochemical, Biochemical, and Molecular Methods. Methods in molecular biology (Clifton, NJ). 2016;1366:517-532.

\section{Figures}

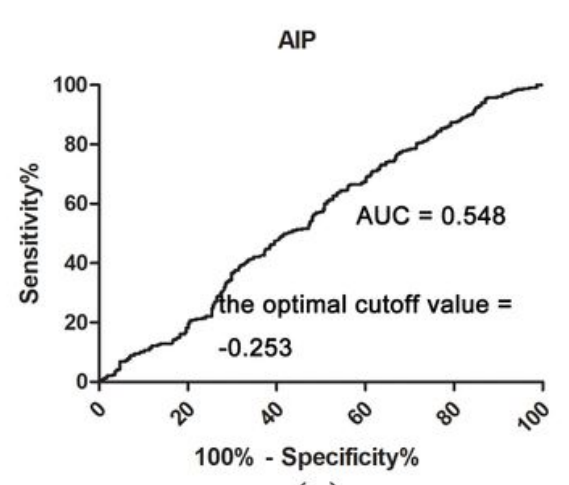

(a)

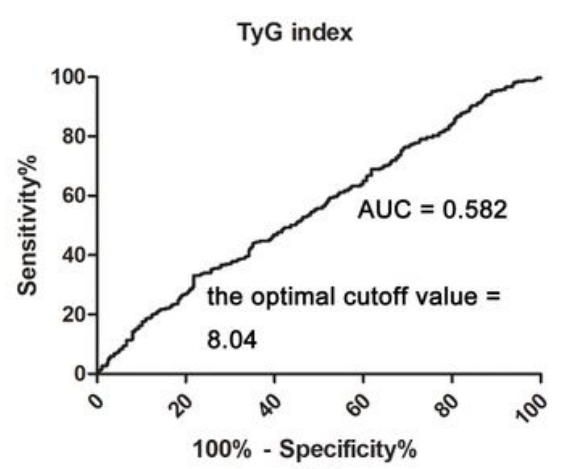

(b)

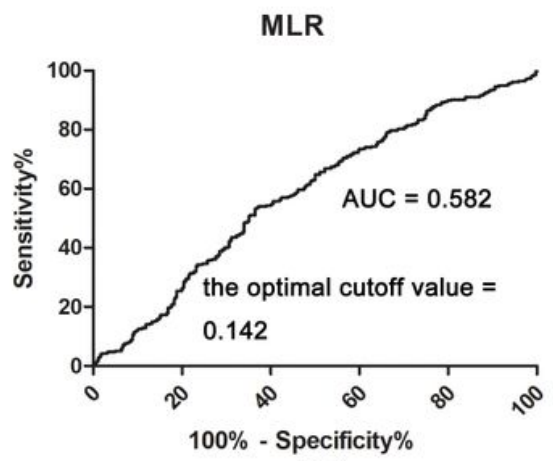

(c)

\section{Figure 1}

Receiver operating characteristic curve analysis of the AIP (a), TyG index (b), and MLR (c).

\section{Supplementary Files}

This is a list of supplementary files associated with this preprint. Click to download. 
- certificates.pdf

Page 15/15 